\title{
BMJ Open Healthy eating and physical activity environments in out-of-school hours care: an observational study protocol
}

\author{
Ruth Crowe (D) ,,2 Yasmine Probst (D) ,2 Jennifer Norman, ${ }^{2,3}$ Susan Furber, ${ }^{2,3}$ \\ Lisa Franco, ${ }^{2,3}$ Rebecca M. Stanley, ${ }^{2,4}$ Cecilia Vuong, ${ }^{5}$ Karen Wardle, ${ }^{5}$ \\ Marc Davies, ${ }^{6}$ Sarah Ryan, ${ }^{4}$ Anthony D. Okely ${ }^{4}$
}

To cite: Crowe R, Probst $Y$, Norman J, et al. Healthy eating and physical activity environments in out-of-school hours care: an observational study protocol. BMJ Open 2020;10:e036397. doi:10.1136/ bmjopen-2019-036397

- Prepublication history for this paper is available online. To view these files, please visit the journal online (http://dx.doi. org/10.1136/bmjopen-2019036397).

Received 06 January 2020 Revised 23 April 2020 Accepted 23 July 2020
Check for updates

(c) Author(s) (or their employer(s)) 2020. Re-use permitted under CC BY-NC. No commercial re-use. See rights and permissions. Published by BMJ.

For numbered affiliations see end of article.

Correspondence to

Ruth Crowe;

rc101@uowmail.edu.au

\section{ABSTRACT}

Introduction Childcare settings have been widely identified as important venues for promoting healthy lifestyles to children. Out-of-school hours care (OSHC) is a rapidly growing childcare service, yet there has been limited research reported on healthy eating and physical activity (HEPA) environments within the Australian OSHC setting. This research aims to describe the HEPA environments related to foods and beverages served, staff behaviours and child physical activity levels across two local health districts within New South Wales, Australia. This study will provide evidence to support future interventions and policies in Australian OSHC settings. Methods and analysis A cross-sectional study design will be used to describe the food and beverages provided and child activity levels, and report on environmental correlates. OSHC programmes will be visited on nonconsecutive weekdays between 2018 and 2020. The frequency of foods and beverages offered will be observed and categorised into food groups aligned to the Australian Dietary Guidelines. Children's physical activity will be measured using ActiGraph wGT3X-BT accelerometers. Staff behaviour will be captured via direct observation and the System for Observing Staff Promotion of Activity and Nutrition. Short interviews with programme directors will gather contextual information about OSHC practices and policies.

Ethics and dissemination Findings will be disseminated through peer-reviewed scientific journals, conference presentations and individualised feedback to each participating service. Ethical approval was granted by the University of Wollongong Human Research Ethics Committee (HE17/490).

\section{INTRODUCTION}

Healthy body weight in childhood supports optimal bone development, cognition and concentration at school, improved sleep patterns, and reduced anxiety and depression in later life. ${ }^{1}$ Healthy eating and physical activity (HEPA) are important in maintaining a healthy weight status. ${ }^{2}{ }^{3}$ National data indicate that no Australian children (aged 4-8 years) currently meet the vegetable intake recommendations, while most exceed

\section{Strengths and limitations of this study}

- This will be one of the first known Australian studies to systematically describe the healthy eating and physical activity environments within before-school and afterschool programmes to support the development of future interventions, better policies and healthier environments for children attending outof-school hours care (OSHC) programmes.

- Foods observed can only provide an estimation of food groups offered, rather than actual foods consumed by the children.

- OSHC programmes from the two local health districts in New South Wales may not be representative of all OSHC programmes across New South Wales or Australia.

discretionary food intake guidelines. ${ }^{4}$ Nearly half of Australian children are not meeting physical activity guidelines and nearly threequarters exceed the recommendations for recreational screen-time. ${ }^{5}$ The out-of-school hours' time period may be a critical window in a child's day to intervene, as studies have shown children consume large amounts of snack foods ${ }^{6}$ and participate in long periods of screen-based sedentary activities ${ }^{78}$ during out-of-school hours.

In Australia, out-of-school hours care (OSHC) programmes operate before school (06:00-09:00), after school (15:00-18:00) and during school holidays (vacation care) (09:00-18:00). OSHC programmes are of growing importance for many Australian parents whose employment requires them to work outside school hours. ${ }^{910}$ In 2018, 36\% of Australian children in care attended OSHC programmes (458750 children), spending an average of 12 hours per week in these programmes. ${ }^{9}$ OSHC programmes have the opportunity to provide positive physical and social environments that can promote healthy eating and active play to children who attend. 
Within an OSHC setting, staff can create supportive physical environments through (1) the foods and beverages available to children (provided meals, vending machines and food rewards), (2) health-promoting messages $^{11}{ }^{12}$ (via posters, nutrition education and cooking), and (3) opportunities and equipment for active play. The social environment can influence behaviour via staff role-modelling ${ }^{11}$ (eg, consumption of healthy foods and beverages and engagement in physical activity opportunities) and establishing HEPA practices as a social norm within these settings through the presence of strong and supportive policies.

While limited studies have reported on HEPA within before-school care ${ }^{1314}$ and Australian OSHC programmes, international research has found that foods and beverages served and children's physical activity levels within afterschool programmes fell well below national recommendations. ${ }^{15} 16$ This research aims to describe the HEPA environments related to the foods and beverages served, staff behaviours and child physical activity levels across two local health districts within New South Wales, Australia.

\section{METHODS}

A cross-sectional, observational study will be conducted to (1) observe the foods and beverages offered to children; (2) assess the level of physical activity of children; and (3) observe staff behaviours on promotion and rolemodelling of HEPA within OSHC programmes. Data will be collected during unannounced (non-specified) visits on non-consecutive weekdays to ensure usual behaviour of staff is captured. In the occurrence of unfavourable weather patterns (eg, heavy rainfall), which may lead to irregular practices or changes to the usual programme, observations will be rescheduled. Data collection methods are outlined in figure 1. Data are scheduled to be completed within the afterschool programmes between March 2018 and April 2019 and within before-school care from February 2020 to December 2020.

\section{Study sample}

In 2018, there were 243 OSHC providers in operation across the South Western Sydney and Illawarra Shoalhaven local health districts, ${ }^{17}$ which will act as the sampling frame. Of these, 204 OSHC programmes are eligible to participate based on the following criteria: five or more primary school-aged children (5-12 years) enrolled; the programme runs from 06:00 to 09:00 and/or from 15:00 to 18:00 during school terms; provide at least one breakfast or afternoon meal; and the programme is not exclusively advertised as a homework or physical activity-related club (eg, dance academy, swimming or football clubs).$^{18} \mathrm{~A}$ power calculation and sample size estimation were generated with $5 \%$ precision requiring 128 OSHC programmes to be recruited. Given the large sample size required, all eligible services in the two local health districts will be invited to participate via email and telephone.

\section{Recruitment}

Written informed consent will be obtained from OSHC directors. Data collected from a service will primarily consist of observing (1) staff behaviour, interactions and involvement during OSHC programmes; (2) food and beverages provided; and (3) physical activity opportunities. Due to the observational nature of this research, methods have been determined as low risk. ${ }^{19} \mathrm{~A}$ passive consent approach, however, will be applied for collecting accelerometry data. Children will be invited to wear an accelerometer for the duration of their time in the programme, unless parents/guardians have opted their

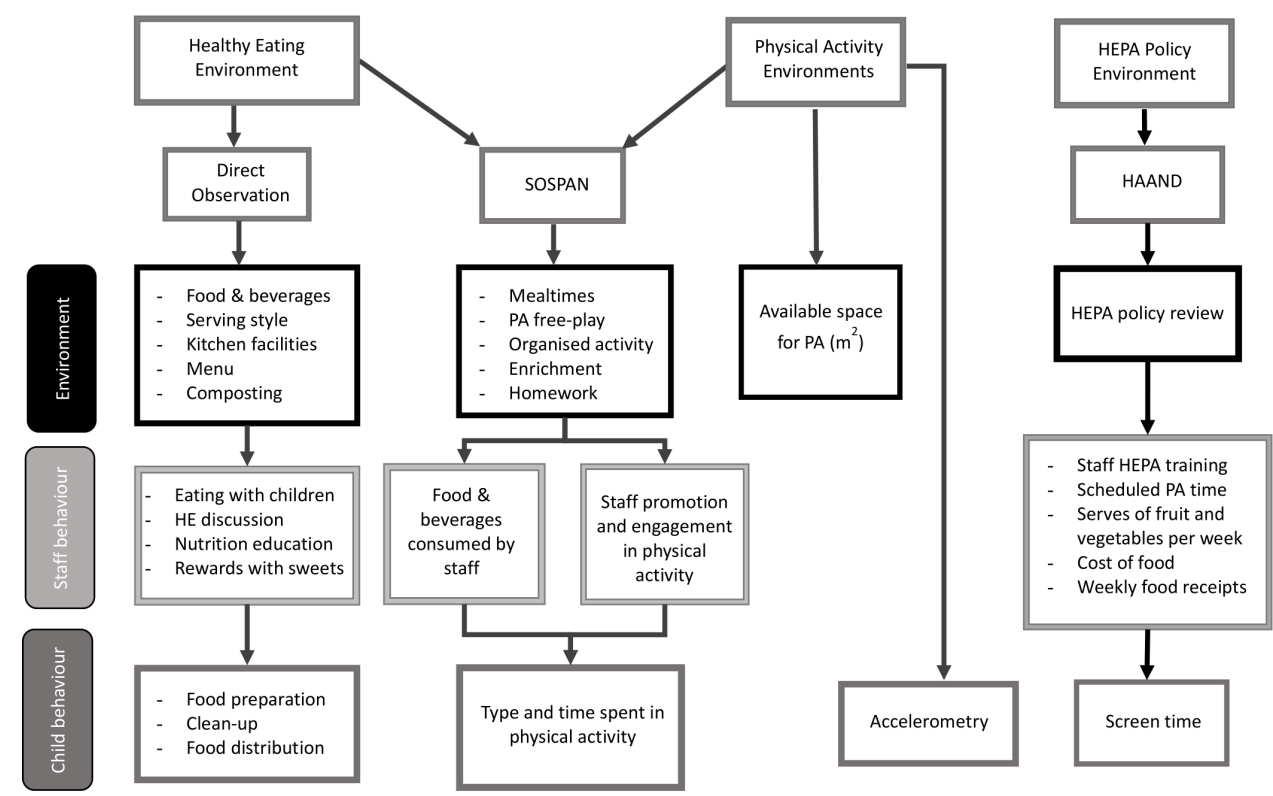

Figure 1 Data collection methods for observing the HEPA environments within out-of-school hours care. HAAND, Healthy Afterschool Activity and Nutrition Document; HE, healthy eating; HEPA, healthy eating and physical activity; PA, physical activity; SOSPAN, System for Observing Staff Promotion of Activity and Nutrition. 
child out of wearing an accelerometer. A child can refuse assent at any stage of the research process. Staff and parents will be notified of the study via several channels, including (1) recruitment video, digital research posters and information sheets shared via OSHC internal communication avenues; (2) research notification posters at each entrance way, notice boards and sign in/out desk within each OSHC; and (3) participant information sheets and opt-out forms (which provide detailed explanation of the research study, investigator contact details and the opportunity for participants to be excluded from the study) located at sign in/out desks. Information relating to this study will be displayed for a minimum of 2 weeks prior to data collection commencing and for the duration of the data collection period. Data collectors will be on-site during data collection and available to discuss the study with staff and parents as required.

\section{Context}

In 2010, the National Quality Framework was implemented in Australia as the overarching regulatory framework for early childhood education and care, under which sit OSHC services. ${ }^{20}$ Within this framework are seven National Quality Standards that are underpinned by National Legislation and Regulations. ${ }^{20}$ HEPA fall under the National Quality Standards 2, Element 2.1.3: 'healthy eating and physical activity are promoted and appropriate for each child'. The Australian Children's Education and Care Quality Authority disseminated the Guide to the National Quality Standard ${ }^{20}$ to support service providers in meeting the requirements of the National Quality Standards. These guidelines within the National Quality Framework are not authoritative, but provide flexibility on how service providers might meet the Standards. ${ }^{21}$ As demonstrated in table 1, this guide describes best practice guidelines for education and care services, recommending staff use positive role-modelling behaviours, engage children in healthy eating conversations, use cooking experience to build knowledge, provide meals consistent with the Australian Dietary Guidelines, implement frequent opportunities for physical activity and role-model enjoyment by engaging in activities. ${ }^{20}$ A combination of resources designed to support OSHC programmes in meeting quality area 2 will be used to guide the criteria within this study, including (1) Heart Foundation's 'Eat Smart, Play Smart' manual, ${ }^{22}$ (2) Nutrition Australia's 'Healthy eating in the National Quality Standards' ${ }^{23}$ and (3) the 'Food and drink checklist for outside school hours care'. ${ }^{24}$ For the purpose of this study we will report on whether staff behaviour relating to the best practice guidelines was observed or not.

HEPA measures were selected from the Australian Dietary Guidelines ${ }^{25}$ and the Australian Physical Activity and Sedentary Behaviour Guidelines for Children and Young People, respectively. ${ }^{26}$ Due to the observational nature of this study, the frequency of food groups offered/ served to children will be reported. National physical activity guidelines state that children should accumulate a minimum of $60 \mathrm{~min}$ of moderate-to-vigorous physical activity (MVPA) across an entire day. ${ }^{26}$ For the current study, a minimum measure of $30 \mathrm{~min}$ of MVPA has been selected as the criterion. ${ }^{26}$ This amount of time is half of the daily recommendation. It is also recognised internationally as an achievable goal specifically within the afterschool period ${ }^{27}$ and has been used in studies conducted in similar settings in the USA. ${ }^{1828} 29$

\section{Healthy eating environment}

Food and beverages offered to children will be captured via direct observation and digital images. Digital images will capture descriptive data for the provided foods, including food labels, branding, packaging and serving methods (individual portion sizes or 'family style', characterised by a shared platter). ${ }^{30} 31$ Trained nutritionists or final-year nutrition and dietetics graduate students will collect all food and nutrition behavioural observation data. Water will be recorded as available if cups of water or designated water stations are available to children during the snack time or throughout the programme. ${ }^{31}$

Observations of the healthy eating environment will be made during the scheduled mealtime, including staff healthy eating promotion behaviours; staff sitting and eating with children; staff promotion/discouragement of healthy foods and beverages; staff engaging children in healthy eating discussions or nutrition education during mealtime; provision of food knowledge and skills development (including children's involvement in the food preparation activities and food clean-up); rewarding of good behaviour with discretionary food items ${ }^{22}$ (eg, sweets and confectionery); and food waste management (eg, use of a compost or worm farm). Weekly food menus will be observed and recorded, including if they are displayed for parents, whether menus were consistent with foods served and if they met the requirements of the 'Food and drink checklist for outside school hours care'. ${ }^{24}$ Types of food preparation (kitchen) facilities will be observed and documented, including food storage, cooking equipment, preparation areas and washing-up facilities.

\section{Physical activity environments}

Prior to data collection, all OSHC programmes will be visited to record the physical characteristics of the programme environment, including indoor (nonphysical activity enrichment or snack areas) and outdoor physical activity spaces. These spaces will be divided and identified as zones during the data collection period. Available space accessible to children during the OSHC programme will be mapped and measured in metres using a Craftright measuring wheel (figure 2). Permanent facilities (eg, basketball courts, fixed equipment and sandpits) will be measured and identified as zones.

Child physical activity will be measured via ActiGraph accelerometers (wGT3X-BT models). Accelerometers are widely used to provide an objective estimate of physical activity in free-living research. ${ }^{29} 3233$ Accelerometers are small, unobtrusive devices that sit around a child's waist, 
Table 1 Best practice guidelines, selected from the Guide to the National Quality Standards for reporting of HEPA promotion behaviours in OSHC

\begin{tabular}{|c|c|c|c|c|}
\hline National Quality Standards & $\begin{array}{l}\text { Direct } \\
\text { observation }\end{array}$ & SOSPAN & Accel & HAAND \\
\hline \multicolumn{5}{|l|}{ Healthy eating environment } \\
\hline $\begin{array}{l}\text { Engage children in experiences and conversations that promote } \\
\text { mealtimes to be enjoyable and promote healthy, balanced lifestyles. }\end{array}$ & $\checkmark$ & & & \\
\hline \multicolumn{5}{|l|}{$\begin{array}{l}\text { Use cooking experiences to further children's understanding of food and } \\
\text { nutrition. }\end{array}$} \\
\hline Never use food to reward children. & $\checkmark$ & $\checkmark$ & & \\
\hline $\begin{array}{l}\text { Sit and eat with children and model healthy eating and nutrition } \\
\text { practices during mealtimes. }\end{array}$ & $\checkmark$ & & & \\
\hline $\begin{array}{l}\text { Provide food and beverages consistent with the Australian Dietary } \\
\text { Guidelines. }\end{array}$ & $\checkmark$ & & & $\checkmark$ \\
\hline Provide foods and drinks consistent with the menu. & $\checkmark$ & $\checkmark$ & & $\checkmark$ \\
\hline Access to water throughout the day. & $\checkmark$ & $\checkmark$ & & \\
\hline \multicolumn{5}{|l|}{ Physical activity environment } \\
\hline $\begin{array}{l}\text { Implement physical games and activities as part of the programme and } \\
\text { encourage children to participate. }\end{array}$ & & $\checkmark$ & & \\
\hline $\begin{array}{l}\text { Become involved and demonstrate enjoyment in children's physical } \\
\text { activity. }\end{array}$ & & $\checkmark$ & & \\
\hline Children should have frequent opportunities to engage in active play. & & $\checkmark$ & & $\checkmark$ \\
\hline Children should lead physical play activities with peers. & & $\checkmark$ & & \\
\hline $\begin{array}{l}\text { Opportunity for dance, creative movement and drama and respond to } \\
\text { music. }\end{array}$ & & $\checkmark$ & & $\checkmark$ \\
\hline $\begin{array}{l}\text { Provide resources and equipment to support children to participate in } \\
\text { physical activity. }\end{array}$ & & $\checkmark$ & & \\
\hline
\end{tabular}

Additional measures*

Nutrition and physical activity policies.

Children accumulate 30 min MVPA in the hours before and after school.

Annual nutrition and physical activity staff training.

This is not an exhaustive list of best practice behaviours, only those that could be reported on by the selected tools used within this study. Some of the descriptions have been summarised within this table.

*Additional measures are not found within the Guide to the National Quality Standards.

Accel, accelerometer; HAAND, Healthy Afterschool Activity and Nutrition Document; HEPA, healthy eating and physical activity; MVPA, moderate-to-vigorous physical activity; OSHC, out-of-school hours care; SOSPAN, System for Observing Staff Promotion of Activity and Nutrition.

attached using adjustable elastic belts. As children arrive at a programme, the accelerometers will be fitted around their waist by trained data collectors, ensuring the unit is sitting on the right hip. The time-on and demographic data of each child (school grade and sex) will be recorded. As children depart from the programme, accelerometers will be removed and time-off recorded. ${ }^{34}$

System for Observing Staff Promotion of Activity and Nutrition Staff promotion of HEPA behaviours will be measured by direct observation and momentary time sampling using the System for Observing Staff Promotion of Activity and Nutrition (SOSPAN) instrument. ${ }^{35}$ SOSPAN is a validated observation tool created and used within afterschool programmes in the USA. ${ }^{34}$ The tool is designed to capture 13 physical activity and 6 healthy eating behaviours of staff, as described in detail elsewhere. ${ }^{34}$ Staff behaviours captured by SOSPAN include staff encouragement of physical activity (eg, leading physical activity, verbally promoting physical activity, staff engagement in physical activity with children and providing children with multiple physical activity options) or discouragement of physical activity (eg, idle time, providing elimination games, children standing or waiting for a turn and withholding physical activity). SOSPAN captures the context of the programme, documenting the duration of scheduled activities (physical activity, indoor enrichment activities, homework/academics and mealtime). Other contextual activities recorded by SOSPAN include the identification of organised activity (structured activity set up by OSHC staff) versus physical activity free-play (unstructured 


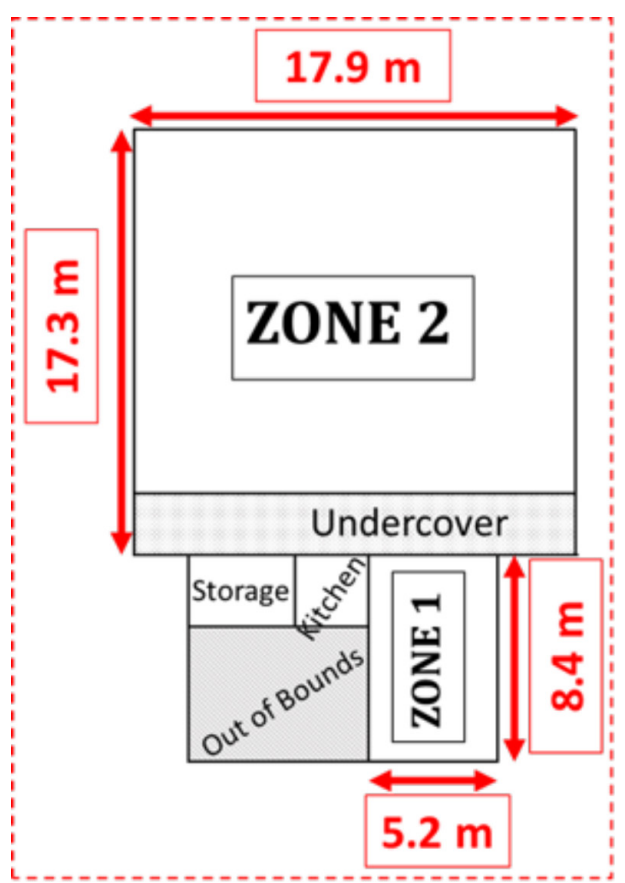

Figure 2 An example of the zones and the size of zones measured in metres $(\mathrm{m})$ in the out-of-school hours care programme.

activity time that was child-led and not organised by staff in the afterschool programmes).

Staff promotion and modelling of healthy eating behaviours are captured in SOSPAN via staff verbally promoting healthy eating, educating children on healthy eating and consuming healthy food and beverage options, or discouraging healthy eating by staff consuming inappropriate foods or drinks.

Systematic SOSPAN scans will be continually completed throughout the duration of the programme or until there are less than five children remaining in the programme. ${ }^{35}$ Data collectors will move systematically between zones (figure 2) where both staff and children are present, completing five scans before moving to the next area. ${ }^{345}$ Data collectors will be required to meet greater than $80 \%$ inter-rater reliability agreement via an interval-by-interval agreement on two consecutive data collection days. ${ }^{35}$ Inter-rater reliability will be continuously monitored throughout the data collection process, completing a minimum of five reliability scans per day.

\section{HEPA policy environment: Healthy Afterschool Activity and Nutrition Documentation}

Written HEPA policies that use clear language to guide staff practices have been shown to improve the HEPA environments within childcare services. ${ }^{36}$ The Healthy Afterschool Activity and Nutrition Documentation (HAAND) instrument is a validated tool that will be used to guide and collect information on HEPA policies and practices through a short interview with directors from each OSHC programme. Detailed information on this tool has been published elsewhere. ${ }^{38}$ HAAND explores 11 healthy eating and 10 physical activity policy characteristics captured through a short, structured interview that is conducted on-site with the OSHC directors by trained data collectors. In short, HAAND evaluates the level at which programme policies support HEPA characteristics through written policies, staff training, use of HEPA resources, time allocations and types of physical activity, healthy eating practices, and screen-time availability. In addition, a copy of the nutrition and physical activity policies, as well as weekly food receipts and menus, will be requested from each OSHC programme. For the purpose of collecting HEPA policy information, HAAND will be applied to both before-school and afterschool OSHC programmes. To minimise potential response bias, all staff will be reminded at the commencement of the interview that all data collected will be deidentified and the importance of not modifying any of their behaviours.

\section{Training}

Data collectors will be extensively trained in all data collection methods prior to data collection commencing. This will occur via a combination of classroom simulation and practical on-site training at local, non-participating OSHC programmes. Theoretical classroom training will include the review of study protocols, memorising observational codes and watching video clips depicting the outof-school hours environment and coding scenarios using observational tools, developed by Weaver et al. ${ }^{34}$ Data collection will be primarily conducted by $\mathrm{PhD}$ candidates, nutrition and dietetics final-year graduate students and research assistants.

\section{Data analysis}

Foods and beverages will be categorised by a dietitian or nutritionist into the five food groups according to the Australian Dietary Guidelines : fruit, vegetables, lean meats, dairy and grains (whole grains). Additional categories of discretionary items, refined grains, water and 'extra' drinks (fruit juice, cordial, soft drinks and flavoured milk) will also be recorded. Food categorisation will be guided by the Australian Health Survey food classification system, ${ }^{39}$ and the discretionary food listing ${ }^{40}$ supported by the AUSNUT 2011-13 food composition database. ${ }^{39}$ Food categories will be checked by a researcher independent of the OSHC observations. The frequency of food groups and beverages offered across observation days will be calculated and expressed as percentage, mean and SD for normally distributed data, and median and IQR for skewed data. Data transformation is not deemed relevant to this study.

Accelerometer-derived physical activity data will be calculated for minutes per day spent in sedentary, total physical activity and MVPA. For this study the Evenson cut points will be used: sedentary behaviour $<26$ counts $/ 15 \mathrm{~s}$, light-to-moderate activity $26-573$ counts $/ 15 \mathrm{~s}$, moderate activity 574-1002 counts $/ 15 \mathrm{~s}$, and vigorous activity $>1002$ counts $/ 15 \mathrm{~s} .{ }^{33}$ The Evenson cut points have been recognised as accurate cut points for measuring the time spent in different physical activity intensities for children aged 5-8 years. ${ }^{32}$ Within afterschool programmes, physical 
activity data will be considered valid if the total wear time of accelerometers is equal to or greater than $60 \mathrm{~min}^{16}$ and 30 min within before-school care. Total time active will be reported on for the before-school care programmes. All accelerometry data will be analysed using ActiLife software $^{41}$ and STATA V. 15.1. ${ }^{42}$

Staff behaviours captured through direct observation, SOSPAN and responses from the structured interview (ie, HAAND) will be quantified and reported as a percentage of observations and responses completed using SPSS V.25.0 software.

The relationship between serving healthy snack foods and variables such as socioeconomic index for areas, availability of kitchen facilities and healthy eating training of staff will be explored.

To explore the relationships between the physical activity environment and child activity levels, correlations between time spent in MVPA, total physical activity and sedentary behaviour will be assessed against physical activity policy, staff engagement in physical activity, available space for physical activity $\left(\mathrm{m}^{2}\right)$, ratio of the number of children to staff, physical activity equipment and sex of the child.

\section{ETHICS AND DISSEMINATION}

Ethical approval has been provided by the University of Wollongong, Australia Human Research Ethics Committee (approval HE17/490). Results from this study will be disseminated through peer-reviewed scientific journals, conference presentations, scientific reports and service reports (providing findings to participating OSHC care providers) and will form part of student dissertations.

\section{PATIENT AND PUBLIC INVOLVEMENT}

Although this research was completed without public involvement, it did incorporate key public health stakeholders in the governance and management of the study. These stakeholders did contribute to the research priorities, defining research question and outcome measures and providing input into the study design. Members of the public were not invited to comment on the study design and were not consulted to ensure a true benchmark was achieved. Members of the public were not invited to contribute to the writing or editing of this document for readability or accuracy.

\section{Author affiliations}

${ }^{1}$ School of Medicine, Science Medicine and Health, University of Wollongong, Wollongong, New South Wales, Australia

${ }^{2}$ Illawarra Health and Medical Research Institute, University of Wollongong, Wollongong, New South Wales, Australia

${ }^{3}$ Health Promotion Service, Illawarra Shoalhaven Local Health District, Wollongong, New South Wales, Australia

${ }^{4}$ Early Start, School of Education, University of Wollongong, Wollongong, New South Wales, Australia

${ }^{5}$ Health Promotion Service, South Western Sydney Local Health District, Liverpool, New South Wales, Australia

${ }^{6}$ NSW Healthy Children Initiative, NSW Office of Preventive Health, Liverpool, New South Wales, Australia
Twitter Ruth Crowe @Ruth_Crowe101, Yasmine Probst @YasmineProbst, Rebecca M. Stanley @rstanley_m and Anthony D. Okely @tonyokely

Acknowledgements We acknowledge Julie Parkinson and Christine Innes-Hughes for their contribution as part of the Prevention Research Support Program working committee, offering valuable insight and context to the research study.

Contributors $\mathrm{RC}$ is a PhD candidate of this study. She has worked with the research team developing the study design and methodology, and will be the lead on data collection and analysis, interpretation, and drafting of future manuscripts. $\mathrm{YP}$ and RMS are PhD supervisors on this project. They have contributed to the study design and provided support through the development of this study, and both revised and edited the manuscript. JN, SF, LF, CV, KW and MD are part of the Prevention Research Support Program working committee, offering insight and context of local health districts. They have also revised and made significant editorial contributions to this manuscript. SR is the project manager who has provided administrative support to assist the progression of this project. TO is the chief investigator of this study, contributing to the study design and methodologies. $\mathrm{He}$ is a PhD supervisor on this project and has revised and edited this manuscript. All authors have read and approved the final manuscript. This manuscript has not been submitted or published in any other journal.

Funding This work was supported by the Prevention Research Support Program, funded by the New South Wales Ministry of Health. This research has been conducted with the support of the Australian Government Research Training Program Scholarship.

Disclaimer The opinions expressed in this paper are those of the authors and do not represent any external corporation.

Competing interests None declared.

Patient and public involvement Patients and/or the public were not involved in the design, or conduct, or reporting, or dissemination plans of this research.

Patient consent for publication Not required.

Provenance and peer review Not commissioned; externally peer reviewed.

Open access This is an open access article distributed in accordance with the Creative Commons Attribution Non Commercial (CC BY-NC 4.0) license, which permits others to distribute, remix, adapt, build upon this work non-commercially, and license their derivative works on different terms, provided the original work is properly cited, appropriate credit is given, any changes made indicated, and the use is non-commercial. See: http://creativecommons.org/licenses/by-nc/4.0/.

\section{ORCID iDs}

Ruth Crowe http://orcid.org/0000-0003-1439-8681

Yasmine Probst http://orcid.org/0000-0002-1971-173X

\section{REFERENCES}

1 Engle P, Huffman SL. Growing children's bodies and minds: maximizing child nutrition and development. Food Nutr Bull 2010;31:S186-97.

2 Australian Institute of Health and Welfare. Overweight \& obesity, 2019. Available: www.aihw.gov.au/reports-data/behaviours-riskfactors/overweight-obesity/overview [Accessed 19 Jul 2019].

3 Australian Institute of Health and Welfare. Physical activity, 2019. Available: www.aihw.gov.au/reports-data/behaviours-risk-factors/ physical-activity/overview [Accessed 19 Jul 2019].

4 Australian Bureau of Statistics, Australian Health Survey. Consumption of food groups from the Australian dietary guidelines, 2011-12.Canberra, 2016. Available: www.abs.gov.au/ausstats/ abs@.nsf/Lookup/by\%20Subject/4364.0.55.012 2011-12 Main\% 20Features Vegetables, \%20legumes\%20and\%20beans 10 [Accessed Jul 2019].

5 Australian Bureau of Statistics, Australian Health Survey. Physical activity, 2011-12.Canberra, 2013. Available: www.abs.gov.au/ ausstats/abs@.nsf/Lookup/4364.0.55.004Chapter1002011-12 [Accessed Jul 2019].

6 Wang D, van der Horst K, Jacquier EF, et al. Snacking patterns in children: a comparison between Australia, China, Mexico, and the US. Nutrients 2018;10:nu10020198.

7 Arundell L, Fletcher E, Salmon J, et al. A systematic review of the prevalence of sedentary behavior during the after-school period among children aged 5-18 years. Int J Behav Nutr Phys Act 2016;13:93. 
8 Arundell L, Hinkley T, Veitch J, et al. Contribution of the After-School period to children's daily participation in physical activity and sedentary behaviours. PLoS One 2015;10:e0140132.

9 Department of Education and Training, Australian Government. Early childhood and child care in summary: June quarter 2018, 2018: 2-18.

10 Australian Institute of Health and Welfare, Australian Government. Children in child care and preschool programs.Canberra, 2017. Available: www.aihw.gov.au/reports/australias-welfare/childcare-andearly-childhood-education [Accessed May 2019].

11 Story M, Kaphingst KM, Robinson-O'Brien R, et al. Creating healthy food and eating environments: policy and environmental approaches. Annu Rev Public Health 2008;29:253-72.

12 French SA, Stables G. Environmental interventions to promote vegetable and fruit consumption among youth in school settings. Prev Med 2003;37:593-610.

13 Maher C, Virgara R, Okely T, et al. Physical activity and screen time in out of school hours care: an observational study. BMC Pediatr 2019;19:283.

14 Thompson E, Cooper C, Flanagan C, et al. Food and activity in out of school hours care in Victoria. Nutrition \& Dietetics 2006;63:21-7.

15 Beets MW, Weaver RG, Tilley F, et al. Salty or sweet? nutritional quality, consumption, and cost of snacks served in afterschool programs. J Sch Health 2015;85:118-24.

16 Beets MW, Rooney L, Tilley F, et al. Evaluation of policies to promote physical activity in afterschool programs: are we meeting current benchmarks? Prev Med 2010;51:299-301.

17 Australian Children's Education, Care Quality Authority. National registers, 2019

18 Beets MW, Weaver RG, Turner-McGrievy G, et al. Making healthy eating policy practice: a group randomized controlled trial on changes in snack quality, costs, and consumption in After-School programs. Am J Health Promot 2016;30:521-31.

19 National Health and Medical Research Council. National statement on ethical conduct in human research in government A, 2018.

20 Australian Children's Education \& Care Quality Authority. Guide to the National quality framework. Sydney, 2018: 138-60.

21 McGuire J, Gallegos D, Irvine S. Infant feeding nutrition policies in Australian early childhood education and care services: a content and qualitative analysis. ICEP 2018;12.

22 Heart Foundation. Eat Smart Play Smart - A manual for Out of School Hours Care, 2016: 5-191.

23 Victoria State Government. Healthy eating in the National quality standard. Department of Education and Training, 2019.

24 Healthy Eating Advisory Service. Food and drink checklist for outside school hours care,In: government vs,ed, 2016. Available: https:// heas.health.vic.gov.au/early-childhood-services/menu-planning/ OSHC/checklist [Accessed Feb 2019].

25 National Health and Medical Research Council. Australian dietary guidelines. Canberra, Australia: National health and medical Research Council, 2013. Available: https://www.eatforhealth.gov.au/ guidelines [Accessed Mar 2020].

26 Australian Government Department of Health. Australia's Physical Activity and Sedentary Behaviour Guidelines and the Australian 24
Hour Movement Guidelines, 2019. Available: www1.health.gov.au/ internet/main/publishing.nsf/Content/health-pubhlth-strateg-physact-guidelines [Accessed Jun 2019].

27 California Department of Education. California Afterschool physical activity guidelines. Sacramenta,CA, 2009: 29-30.

28 Beets MW, Shah R, Weaver RG, et al. Physical activity in after-school programs: comparison with physical activity policies. J Phys Act Health 2015;12:1-7.

29 Weaver RG, Beets MW, Hutto B, et al. Making healthy eating and physical activity policy practice: process evaluation of a group randomized controlled intervention in afterschool programs. Health Educ Res 2015;30:849-65.

30 Tugault-Lafleur CN, Black JL, Barr SI. A systematic review of methods to assess children's diets in the school context. Adv Nutr 2017;8:63-79.

31 Beets MW, Weaver RG, Turner-McGrievy G, et al. Compliance With the Healthy Eating Standards in YMCA After-School Programs. J Nutr Educ Behav 2016;48:555-62.

32 Trost SG, Loprinzi PD, Moore R, et al. Comparison of accelerometer cut points for predicting activity intensity in youth. Med Sci Sports Exerc 2011;43:1360-8.

33 Evenson KR, Catellier DJ, Gill K, et al. Calibration of two objective measures of physical activity for children. J Sports Sci 2008;26:1557-65.

34 Weaver RG, Beets MW, Huberty J, et al. Physical activity opportunities in afterschool programs. Health Promot Pract 2015;16:371-82.

35 Weaver RG, Beets MW, Webster C, et al. System for observing staff promotion of activity and nutrition (SOSPAN). J Phys Act Health 2014;11:173-85.

36 Cullen KW, Watson K, Zakeri I. Improvements in middle school student dietary intake after implementation of the Texas public school nutrition policy. Am J Public Health 2008:98:111-7.

37 Slater SJ, Nicholson L, Chriqui J, et al. The impact of state laws and district policies on physical education and recess practices in a nationally representative sample of US public elementary schools. Arch Pediatr Adolesc Med 2012;166:311-6.

38 Ajja R, Beets MW, Huberty J, et al. The healthy afterschool activity and nutrition documentation instrument. Am J Prev Med 2012;43:263-71.

39 Food standards Australia New Zealand. AUSNUT 2011-13 Australian food composition database.Canberra, 2014. Available: www.foodstandards.gov.au/science/monitoringnutrients/ausnut/ Pages/default.aspx [Accessed Apr 2019].

40 Australian Bureau of statistics. Discretionary foods. Australian Health Survey: Users' Guide, 2011-12.Canberra, 2014. Available: www.abs. gov.au/AUSSTATS/abs@.nsf/DetailsPage/4363.0.55.0012011-13? OpenDocument

41 IMB Corp. Ibm SPSS statistics for windows. Armonk,NY: IMB Corp, 2017.

42 StataCorp LLC. Stata statistical software. College Station,TX: StataCorp LLC, 2019. 